\title{
ĐÁNH GIÁ ẢNH HƯởNG CỦA BIẾN ĐộNG SỬ DỤNG ĐẤT ĐẾN DÒNG CHẢY MẠTT VÙNG NÚI PHÍA BẮC LÀO: TÍCH HỢP CÔNG NGHÊ VIỄN THÁM, GIS VÀ MÔ HİNH DIỄN TOÁN DÒNG CHẢY MẠTT CURVE NUMBER
}

\author{
TS. TRÀN TUẤN NGỌC ${ }^{(1)}$, TS. NGHIÊM VĂN TUÁN(1), \\ ThS. NGUYẼ̃N THANH NGA ${ }^{(1)}$, TS. ĐÕ TH! PHƯO'NG THẢO(2) \\ ${ }^{(1)}$ Cục Viễn thám Quốc gia \\ ${ }^{(2)} Đ a ̣ i$ học Mỏ Địa-chất
}

\section{Tóm tắt:}

Mục đích của bài báo là đánh giá ảnh hưởng của biến động sử dụng đất đến dòng chảy mặt trong vòng 15 năm qua phuc vụ công tác giám sát tài nguyên nước mặt khu vực phía Bắc của Lào (gồm 3 tỉnh Vientiane, Xaignabouli, Louanphabang và Thủ đô Vientiane ). Sử dụng ảnh viến thám Landsat7 ETM+ (năm 2000 và 2013) cho phép xác định được biến động lớp phủ nói chung và lớp phủ rừng nói riêng. Tác giả sử dụng phần mềm ENVI để phân loại lớp phủ năm 2000 và 2010 để đánh giá biến động lớp phủ; sử dụng mô hình SWAT với phương pháp đường cong số (Curve Number) để tính toán lưu lượng dòng chảy dưới các điều kiện lớp phủ khác nhau. Kết quả nghiên cứu cho thấy có sự suy giảm đáng kể tổng lưu lượng dòng chảy trong giai đoạn 2000-2010, đặc biệt là trong thời kỳ mùa khô; tác động trực tiếpvà kéo dài thời gian hạn hán ở khu vực phía Bắc của Lào. Trên thực tế, sự suy giảm lưu lượng dòng chảy là do sự suy giảm diện tích rừng ở phía bắc Lào từ cuối những năm 1990 đến nay; nó có liên quan đến việc tăng sự bốc thoát hơ nước và giảm khả năng giữ nước của lớp đất bề mặt ở những khu vực bị mất lớp phủ rừng.

\section{Giới thiệu}

Hầu hết các quá trình biến động sử dụng đất đều có sự ảnh hưởng đáng kể đến tài nguyên và môi trường nói chung, nhất là đối với tài nguyên nước [Nghiêm Văn Tuấn và nnk, 2011; Rachid Nedjai và nnk, 2013]. Ở khu vực phía Bắc của Lào, hiện tượng suy giảm tài nguyên nước mặt có liên quan chặt chẽ đến các hoạt động chặt phá rừng để phục vụ mục đích nông nghiệp, thủy điện,...đã xảy ra trong hơn 20 năm qua. Việc suy giảm diện tích rừng có thể ảnh hưởng tiêu cực đến sự thay đổi chế độ dòng chảy mặt. Để có thể đánh giá được những tác động của biến động lớp phủ/sử dụng đất đến tài nguyên nước, các mô hình thủy văn đã được sử dụng. Các dữ liệu thông tin địa lý của khu vực là hết sức cần thiết và là nguồn dữ liệu đầu vào cho mô hình thủy

Ngày nhận bài: 03/9/2015 văn; các dữ liệu này có thể được xử lý và chiết xuất từ dữ liệu viễn thám kết hợp với hệ thống thông tin địa lý (GIS). Quá trình này cho phép so sánh sự thay đổi tương đối của lớp phủ qua hai thời điểm, hiệu chỉnh mô hình thủy văn và sau cùng là đánh giá sự thay đổi dòng chảy mặt của khu vực phía Bắc Lào trong vòng 15 năm qua. Trong nghiên cứu này, chúng tôi sẽ tập trung vào việc đánh giá mối quan hệ giữa biến động lớp phủ và dòng chảy mặt thông qua việc sử dụng kết hợp công nghệ viễn thám và GIS tích hợp trong mô hình thủy văn (sử dụng phương pháp đường cong số-Curve Number). Quá trình này được thực hiện qua ba bước chính:

a. Bản đồ sử dụng đất năm 2000 và 2010 được thành lập trên cơ sở sử dụng ảnh Landsat7 ETM+ chụp cùng thời gian tương

Ngày chấp nhận đăng: 14/9/2015 
ứng, và được kiểm tra độ chính xác thông qua việc so sánh với dữ liệu kiểm chứng thực địa. Với 2 bản đồ sử dụng đất đã được thành lập, cho phép phân tích biến động sử dụng đất thời kỳ 2000-2010;

b. Tiếp theo, các bản đồ sử dụng đất được chiết xuất từ ảnh viễn thám được tích hợp vào mô hình thủy văn SWAT (Soil and Water Assessment Tool) [Arnold và nnk, 1998] như là một nguồn dữ liệu đầu vào quan trọng để hiệu chỉnh mô hình;

c. Tính toán xu hướng biến động của lưu lượng dòng chảy trong giai đoạn 2000-2010 được sử dụng để chứng minh mối quan hệ giữa biến động sử dụng đất và sự suy giảm của lưu lượng dòng chảy.

\section{Khu vực nghiên cứu}

Khu vực nghiên cứu (hình 1) bao gồm các tỉnh Xaynabouri, Louangphrabang, Vientiane và Thủ đô Vientiane thuộc miền bắc Lào với tổng diện tích là $51.637 \mathrm{~km}^{2}$, chiếm gần $1 / 5$ diện tích Lào. Phía bắc giáp các tỉnh Bokeo, Udonxay và Phongsali; phía Đông giáp tỉnh XiangKhouang, Houaphan và Boulikhamxai; phía Tây và Phía Nam giáp Thái Lan.

Về hệ thống thủy văn: sông Mekong chảy qua khu vực này theo hướng từ Bắc xuống Nam, đến biên giới Thái Lan, dòng sông chuyển sang hướng Tây-Đông Bắc. Trong khu vực nghiên cứu, ngoài dòng chính sông Mekong chảy qua, còn có các dòng nhánh quan trọng của nó như: sông Mae Kok, Nam Khan (Luang Prabang); Nam Song, Nam Ngum và Nam Lik (Vientiane ). Ngoài ra, trong khu vực nghiên cứu có rất nhiều các hồ, trong đó lớn nhất là hồ Nam Ngum.

Về địa hình: Khu vực nghiên cứu có độ cao từ 150 đến $2810 \mathrm{~m}$ (núi Phou Bia). Khu vực phía Tây tương đối hiểm trở với dãy Luang Prabang chạy dọc theo hướng BắcNam, tạo thành biên giới tự nhiên ngăn cách với cao nguyên của Thái Lan.
Về khí hậu, khu vực này có nhiệt độ nóng ẩm, thuộc khu vực nhiệt đới gió mùa, trong năm chia thành hai mùa rõ rệt: mùa mưa từ cuối tháng 4 đầu tháng 5 đến tháng 10 , mùa khô từ tháng 11 đến cuối tháng 4 . Lượng mưa hàng năm dao động trong khoảng 1500-2000 mm. Nhiệt độ trung bình năm khoảng $27^{\circ} \mathrm{C}$. Tháng 3 đến tháng 4 là thời gian nóng nhất trong năm, nhiệt độ có thể đến $38^{\circ} \mathrm{C}$. Từ tháng 11 đến tháng 2 là thời gian có nhiệt độ thấp hơn, các khu vực núi cao có thể xuống tới $10^{\circ} \mathrm{C}$ [DMH].

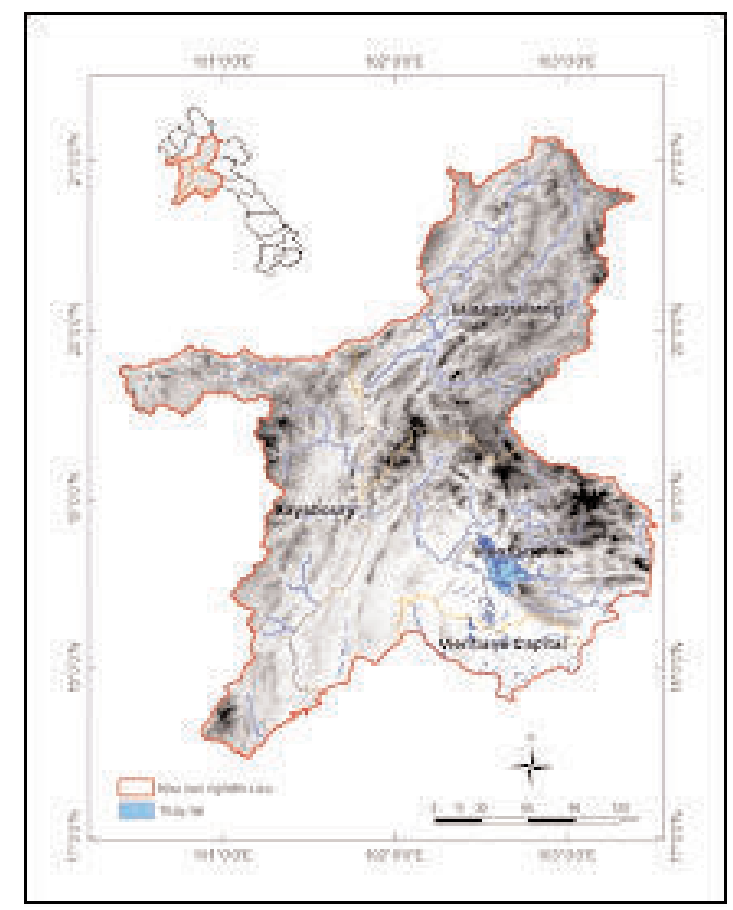

Hình 1: Khu vực nghiên cứu

\section{Phương pháp nghiên cứu}

\subsection{Phương pháp}

Để đạt được các mục tiêu đã đặt ra, một số bước cần thiết thực hiện được trình bày như trong hình 2. Bước đầu tiên, tập trung vào xây dựng các dữ liệu đầu vào cần thiết cho mô hình thủy văn như bản đồ sử dụng đất trên cơ sở ứng dụng viễn thám và hệ thống thông tin địa lý. Giai đoạn thứ hai, là xác định các tham số thủy văn cơ bản 
(HRU) nhằm hiệu chỉnh và kiểm nghiệm mô hình. Phần thứ ba, tiến hành đánh giá ảnh hưởng của sự biến động sử dụng đất đối với dòng chảy mặt.

\subsection{Mô hình Curve Number: đánh giá biến động dòng chảy mặt}

Mô hình SWAT (Soil and Water Assement Tools) là một "Công cụ đánh giá đất và nước" được xây dựng từ những năm 90's bởi Jeff Arnold thuộc trung tâm nghiên cứu đất nông nghiệp USDA. Mô hình này được sử dụng để mô phỏng ảnh hưởng của việc quản lý sử dụng đất đến nguồn nước, bùn cát và hàm lượng chất hữu cơ trong đất trên hệ thống lưu vực sông trong một khoảng thời gian nào đó [Arnold và nnk, 1998]. Xét về toàn lưu vực thì mô hình SWAT là một mô hình phân bố. Mô hình này chia dòng chảy thành 3 pha: pha mặt đất, pha dưới mặt đất (sát mặt, ngầm) và pha trong sông.

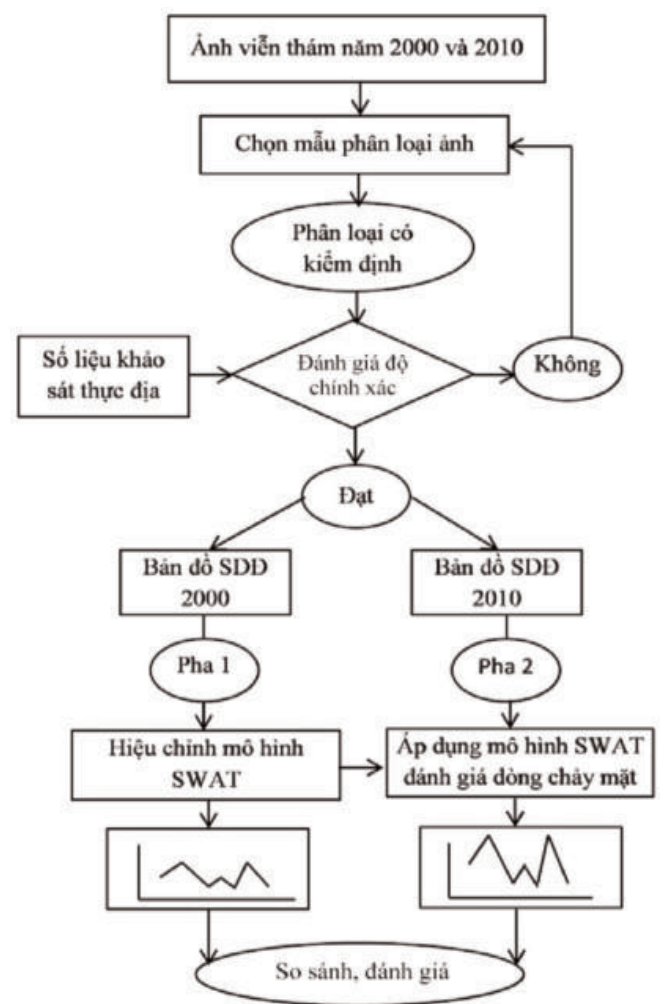

Hình 2: Quy trình đánh giá ảnh hưởng của biến động sử dụng đất đến dòng chảy mặt
Việc mô tả các quá trình thuỷ văn được chia làm hai phần chính: phần thứ nhất là pha lưu vực với chu trình thuỷ văn kiểm soát khối lượng nước, bùn cát, chất hữu cơ và được chuyển tải tới các kênh chính của mỗi lưu vực; phần thứ hai là diễn toán dòng chảy, bùn cát, hàm lượng các chất hữu cơ tới hệ thống kênh và tới mặt cắt cửa ra của lưu vực.

Trong pha lưu vực, mô hình SWAT sử dụng phương pháp đường cong thấm SCS (1972) [SCS, 1972] với mô hình cơ bản Curve Number (đường cong số) để xác định lượng mưa hiệu quả. Phương trình dòng chảy đường cong số là phương trình thực nghiệm, dùng để xác định lượng dòng chảy mặt dưới điều kiện khác nhau về sử dụng đất và loại đất [Arnold và nnk, 1998]. Phương trình đường cong số được viết như sau:

$$
Q_{\text {surf }}=\frac{\left(R_{d a y}-I_{a}\right)^{2}}{\left(R_{d a y}-I_{a}+S\right)}
$$

Trong đó:

$Q_{\text {surf: Lượng dòng chảy mặt hay lượng }}$ mưa hiệu quả (mm); $R_{\text {day: Lượng mưa ngày }}$ $(\mathrm{mm}) ; \mathrm{I}_{\mathrm{a}}$ : Tổn thất thấm ban đầu $(\mathrm{mm}) ; \mathrm{S}$ : Lượng thấm cho phép tối đa có thể trữ trong đất $(\mathrm{mm})$.

Lượng thấm tối đa cho phép phụ thuộc vào đặc tính đất, sử dụng đất và độ ẩm đất tại thời điểm bắt đầu mưa và được xác định như sau:

$$
S=25.4\left(\frac{1000}{C N}-10\right)
$$

Trong đó $\mathrm{CN}$ chỉ số đường cong đại biểu cho đặc tính đất tính cho ngày.

Hệ số tổn thất thấm ban đầu $\mathrm{I}_{\mathrm{a}}=0,2 \mathrm{~S}$ ứng với những trận mưa có cường độ mưa lớn (theo U.S Conservation Service). Khi đó 
phương trình 1.2 được viết thành như sau:

$$
Q_{\text {surf }}=\frac{\left(R_{d a y}-0,2 S\right)^{2}}{\left(R_{d a y}+0,8 S\right)}
$$

Dòng chảy mặt chỉ xuất hiện khi Rday $>$ a. Hệ số $\mathrm{CN}$ được tra trong tài liệu của SCS (1972). Hệ số CN phụ thuộc vào vấn đề sử dụng đất và lớp độ ẩm đất.

Giá trị đường cong $\mathrm{CN}$ trong phương trình 1.3 được viết lại như sau:

$$
C N=\frac{25400}{(S+254)}
$$

Trong đó $\mathrm{CN}$ là chỉ số đường cong tính cho ngày và $S$ là thông số diễn toán tính cho hàm lượng ẩm của đất trong ngày.

Việc áp dụng mô hình SWAT có thể được phân chia ra thành 4 giai đoạn chính: Chuẩn bị dữ liệu (1), Chiết tách tiểu lưu vực (2), Hiệu chỉnh mô hình (3), và Phân tích biến động (4).

\subsubsection{Chuẩn bị dữ liệu}

\section{a. Bản đồ sử dụng đất}

Trong nghiên cứu này các bản đồ sử dụng đất năm 2000 và 2010 được thành lập từ ảnh viễn thám Landsat ETM+ có thời gian tương ứng. Để phủ trùm khu vực nghiên cứu, chúng tôi đã sử dụng 4 cảnh Landsat bao gồm: 2 cảnh Landsat7 ETM + (2000) và 2 cảnh Landsat7 ETM + (2010) được tải về từ trang điện tử của Cơ quan địa chất Hoa Kỳ (USGS). Tất cả ảnh viễn thám được sử dụng là những ảnh trong cùng mùa khô (từ tháng 6 đến tháng 8 ), để giảm các sai số kết quả phân loại do sự ảnh hưởng của yếu tố mùa vụ của thảm thực vật.

Với phương pháp phân loại được áp dụng là phương pháp phân loại có kiểm định với thuật toán xác xuất cực đại (Maximum Likelihood) [Eastman, 2003]; chúng tôi đã tiến hành phân loại và thành lập bản đồ sử dụng đất năm 2000 và năm 2010 cho khu vực nghiên cứu (Hình 2), bao gồm 11 lớp: (1) Rừng thường xanh, (2) Rừng rụng lá, (3) Rừng hỗn giao, (4) Rừng cây bụi, (5) Đất cỏ bụi, (6) Đồng cỏ, (7) Đất ngập nước, (8) Đất nông nghiệp, (9) Đất có công trình xây dựng, (10) Đất trống và (11) nước.

Để đánh giá độ chính xác bản đồ sử dụng đất đã được thành lập, các bản đồ trên được so sánh với với các dữ liệu khảo sát thực địa. Các kết quả đánh giá độ chính xác cho 02 bản đồ sử dụng đất năm 2000 và 2010 được tóm tắt cho thấy, độ chính xác chung của cả 2 bản đồ khoảng $89 \%$; hệ số Kappa của bản đồ năm 2000 và 2010 tương ứng là 0.88 và 0.90 . Theo tiêu chuẩn về độ chính xác, có thể nói bản đồ sử dụng đất năm 2000 và 2010 của khu vực nghiên cứu đạt độ chính xác cao [Anderson và nnk., 1971]. (Xem hinh 3)

\section{tượng}

b. Xây dựng cơ sở dữ liệu dũ̃ liệu khí

Dũ liệu khí tượng được sử dụng trong mô hình SWAT bao gồm lượng mưa hàng ngày, nhiệt độ (cao nhất, thấp nhất), độ ẩm không khí, tốc độ gió và bức xạ mặt trời. Trong nghiên cứu này, lượng mưa, nhiệt độ và tốc độ gió được thu thập từ Ủy ban quốc gia sông Mekong Lào (LNMC), các tham số khí tượng khác như độ ẩm không khí và bức xạ mặt trời được chúng tôi xử lý và xây dựng cho khu vực nghiên cứu thông qua dữ liệu khí tượng toàn cầu trong giai đoạn 1985-2014.

\section{c. Xây dựng dữ liệu thổ nhưỡng}

Mô hình SWAT yêu cầu các đặc tính vật lý của đất như: loại đất, độ ẩm bão hòa, độ thấm thủy lực,... Các dữ liệu này được đưa vào mô hình SWAT thông qua việc nhập dữ liệu bản đồ thổ nhưỡng dạng ".shp". Trong nghiên cứu này, bản đồ thổ nhưỡng tỉ lệ $1 / 100.000$ khu vực phía bắc Lào được thu thập từ (LNMC). 

đo

d. Xây dựng bảng dũ̃ liệu lưu lượng thực

Dữ liệu lưu lượng thực đo được sử dụng để hiệu chỉnh và kiểm nghiệm mô hình SWAT. Trong nghiên cứu này chúng tôi sử dụng số liệu lưu lượng thực đo từ năm 1986 đến năm 2008 tại 02 điểm đo Pakbeng và Luang Prabang, thu thập từ (LNMC). Điểm đo Pakbeng là điểm nằm trên sông NamBeng gần thị trấn Pakbeng, gần vị trí dòng sông Nam-Beng đổ ra dòng chính sông Mekong; trong khi điểm đo Luang Prabang nằm gần thành phố Luang Prabang, trên sông Nam-Khan, một dòng nhánh quan trọng của sông Mekong chảy trên địa phận Lào.

\subsubsection{Chiết tách tiểu lưu vực}

Mô hình số địa hình (DEM) là một nguồn dữ liệu đầu vào cần thiết và quan trọng đối với mô hình SWAT. Trong nghiên cứu này, chúng tôi sử dụng DEM được thành lập từ ảnh viễn thám ASTER, với độ phân giải $30 \mathrm{~m}$, đã được chúng tôi tải về từ trang web của ASTER GDEM. DEM được sử dụng để nội suy, chiết tách các tiểu lưu vực cũng

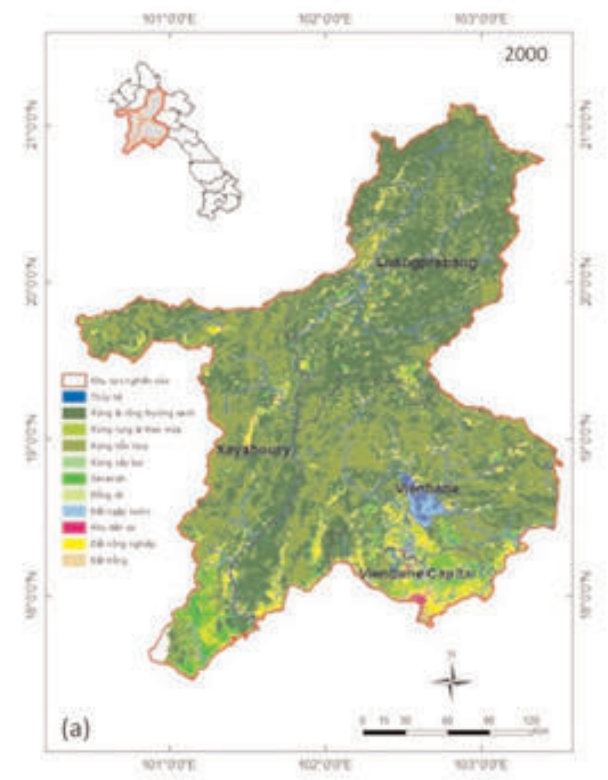

như tính toán các đặc trưng của các tiểu lưu vực (độ rộng, chiều dài, độ dốc, hình thái, vv); và chiết tách hệ thống sông suối cũng như các thông số đặc trưng của chúng (chiều rộng, chiều sâu, độ dốc, .v.v...); đây là những thông số có ảnh hưởng trực tiếp đến tốc độ và hướng của dòng chảy trên bề mặt đất [Shrestha và nnk, 2008].

\subsubsection{Hiệu chỉnh mô hình}

Việc hiệu chỉnh mô hình SWAT được thực hiện bằng cách thay đổi các tham số chính của mô hình, gồm các nhóm bộ thông số: Thông số tính quá trình hình thành dòng chảy mặt (dựa trên phương pháp đường cong số Curve Number), gồm các thông số như tính lượng mưa hiệu quả, các thông số tính lưu lượng đỉnh lũ và các tham số tính hệ số trễ dòng chảy mặt; Thông số tính toán dòng chảy ngầm; Thông số diễn toán trong kênh. Các thông số hiệu chỉnh mô hình được xác định theo phương pháp dò tìm thông số Rosenbrok [Rosenbrok, 1960]. Trong pha hiệu chỉnh mô hình, dữ liệu sử dụng đất năm 2000 đã được sử dụng. Việc đánh giá độ chính xác được thực hiện thông

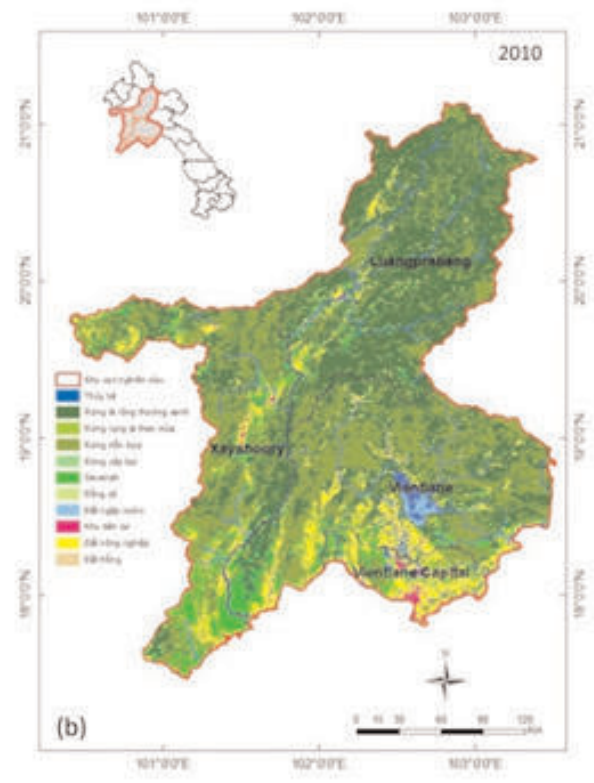

Hình 3: Bản đồ sử dụng đất khu vực phía bắc Lào 
qua đánh giá các tham số thống kê như các hệ số Nash-Sutcliffe, hệ số xác định $\left(\mathrm{R}^{2}\right)$, giá trị phần trăm $\mathrm{pBias}$, và tổng lượng tích lũy dòng chảy.

\subsubsection{Phân tích biến động}

Cơ cấu sử dụng đất trên lưu vực sông biến đổi liên tục, dưới tác động của cả yếu tố tự nhiên và con người. Đối với tài nguyên nước thì biến động sử dụng đất có ảnh hưởng nhất định đến việc phân phối dòng chảy trong năm. Để nghiên cứu ảnh hưởng của biến động sử dụng đất, chúng tôi sẽ sử dụng hai chuỗi số liệu lưu lượng được mô phỏng bởi mô hình SWAT tương ứng với hai dữ liệu sử dụng đất khác nhau: dữ liệu sử dụng đất năm 2000 (pha hiệu chỉnh-pha 1) và 2010 (pha đánh giá biến động-pha 2). Trong đó các giá trị của các thông số của mô hình SWAT trong pha 2 (sử dụng dữ liệu sử dụng đất năm 2010) được giữ nguyên như trong pha 1-pha hiệu chỉnh. Dựa trên tình trạng phân bổ lớp phủ thực vật trên khu vực nghiên cứu, sẽ đưa ra một số giả thiết về biến động sử dụng đất và tính toán diễn biến dòng chảy mặt dưới tác động của sự biến động này.

\section{Kết quả và thảo luận}

\subsection{Hiệu chỉnh mô hình}

Trong nghiên cứu này, quá trình dòng chảy trung bình ngày thực đo tại hai trạm Pakbeng và Luang Prabang được dùng để hiệu chỉnh bộ thông số của mô hình SWAT. Trong pha hiệu chỉnh này, dữ liệu sử dụng đất được thành lập từ ảnh viễn thám năm 2000 đã được sử dụng như là một nguồn dữ liệu đầu vào quan trọng của mô hình. Số liệu lượng mưa được lấy trong giai đoạn 2000-2008 để đưa vào mô hình tính toán. Kết quả hiệu chỉnh các thông số mô hình được thống kê trong bảng 1.

Để đánh giá độ chính xác kết quả mô hình hóa dòng chảy trong pha hiệu chỉnh, số liệu thực đo lưu lượng dòng chảy tại hai trạm Pakbeng và Luang Prabang thời kỳ từ 01/01/2000 đến 31/12/2008 đã được sử dụng để so sánh với số liệu tính toán bởi mô hình SWAT tại hai điểm tương ứng và cùng thời gian. Trong đó, lưu lượng mô hình mô phỏng trong hai năm đầu tiên (năm 2000 và 2001) được coi như giai đoạn ổn định của mô hình, không sử dụng để đánh giá độ chính xác. Lưu lượng dòng chảy mô phỏng trong thời kỳ 2002-2008 được sử dụng để so sánh với lưu thực đo trong cùng giai đoạn để đánh giá kết quả hiệu chỉnh mô hình. Số liệu thống kê đánh giá kết quả hiệu chỉnh mô hình được thể hiện trong bảng 2 . Đường quá trình tính toán và thực đo tại tại trạm đo thuỷ văn Luang Prabang được thể hiện trong hình 4.

Hình 4 cho thấy, nhìn chung dạng đường quá trình dòng chảy tính toán và thực đo có sự phù hợp tương đối tốt. Tổng lượng luỹ tích thực đo trong thời kỳ 2002-2008 tại trạm Luang Prabang là 60.89 tỷ $\mathrm{m}^{3}$, trong khi tổng lượng luỹ tích tính toán là 55.84 tỷ $\mathrm{m}^{3}$ với chênh lệch tương ứng là $8.29 \%$.Tuy nhiên đỉnh lưu lượng tính toán các năm 2006 và 2007 cao hơn giá trị thực đo khá nhiều, điều này có thể được giải thích là do ảnh hưởng của hệ thống hồ chứa nước được xây dựng trong giai đoạn này, trong khi chúng tôi chưa có số liệu về lưu lượng xả của các hồ này để đưa vào hiệu chỉnh mô hình.

Bảng 2: Chỉ số thống kê đánh giá
độ chính xác

\begin{tabular}{|l|c|c|c|}
\hline \multirow{2}{*}{$\begin{array}{l}\text { Giá trị } \\
\text { Tham số }\end{array}$} & \multicolumn{2}{|c|}{ Tính toán } & \multirow{2}{*}{$\begin{array}{c}\text { Tiêu } \\
\text { chuẩn }\end{array}$} \\
\cline { 2 - 3 } & Pakbeng & $\begin{array}{c}\text { Luang } \\
\text { Prabang }\end{array}$ & \\
\hline$R^{2}$ & 0.79 & 0.75 & $0.5-1.0$ \\
\hline $\begin{array}{l}\text { Nash- } \\
\text { Sutcliffe }\end{array}$ & 0.78 & 0.71 & $0.5-1.0$ \\
\hline $\begin{array}{l}\text { Volume erros } \\
\text { (\%) }\end{array}$ & 7.11 & 8.29 & $-/+10$ \\
\hline pBias (\%) & 16.88 & 15.45 & -25 à + 25 \\
\hline
\end{tabular}


Bảng 1: Kết quả hiệu chỉnh bộ thông số cho lưu vực sông

\begin{tabular}{|c|c|c|c|}
\hline Thông số & $\begin{array}{l}\text { Giá trị hiệu } \\
\text { chỉnh }\end{array}$ & Thông số & $\begin{array}{l}\text { Giá trị hiệu } \\
\text { chỉnh }\end{array}$ \\
\hline \multicolumn{2}{|c|}{ Nhóm I: Quá trình hình thành dòng chảy mặt } & \multicolumn{2}{|c|}{ Nhóm II: Dòng chảy ngầm } \\
\hline $\begin{array}{l}\text { CN2: Chỉ số CN úng với điều kiện } \\
\text { ẩm II }\end{array}$ & 61 & $\begin{array}{l}\text { GWQMN: Ngưỡng sinh dòng } \\
\text { chảy ngầm }\end{array}$ & 5 \\
\hline $\begin{array}{l}\text { SOL_AWC: Khả năng trữ nước của } \\
\text { dất }\end{array}$ & 0.10 & $\begin{array}{l}\text { ALPHA_BF: Hề số triết giảm } \\
\text { dòng chảy ngầm }\end{array}$ & 0.05 \\
\hline SOL_K: Độ dẫn thuỷ lực bão hoà & 10 & \begin{tabular}{|} 
GW_DELAY: Thời gian trữ nước \\
tầng ngầm (ngày)
\end{tabular} & 31 \\
\hline $\begin{array}{l}\text { OV_N: Hệ số nhám Manning cho } \\
\text { dòng chảy mặt }\end{array}$ & 15.5 & \multicolumn{2}{|c|}{ Nhóm III: Diễn toán trong kênh } \\
\hline $\begin{array}{l}\text { CH_K(1): Hệ số dẫn thuỷ lực của } \\
\text { kênh dẫn }\end{array}$ & 0.5 & $\begin{array}{l}\text { Chinh } N(2) \text { : Hệ số nhám của kênh } \\
\text { chis }\end{array}$ & 0.05 \\
\hline $\begin{array}{l}\text { CH_N(1): Hệ số nhám kênh dẫn } \\
\left(\mathrm{mm} / \mathrm{g}\left(\mathrm{o}^{\prime}\right)\right.\end{array}$ & 0.025 & $\begin{array}{l}\text { CH_K(2): Hệ số dẫn thuỷ lực củala } \\
\text { kênh chinh (mm/giờ) }\end{array}$ & 0.02 \\
\hline SURLAG: Hệ số trễ dòng chảy mặt & 0.5 & & \\
\hline ESCO: Hệ số bốc hơ của đất & 0.5 & & \\
\hline
\end{tabular}

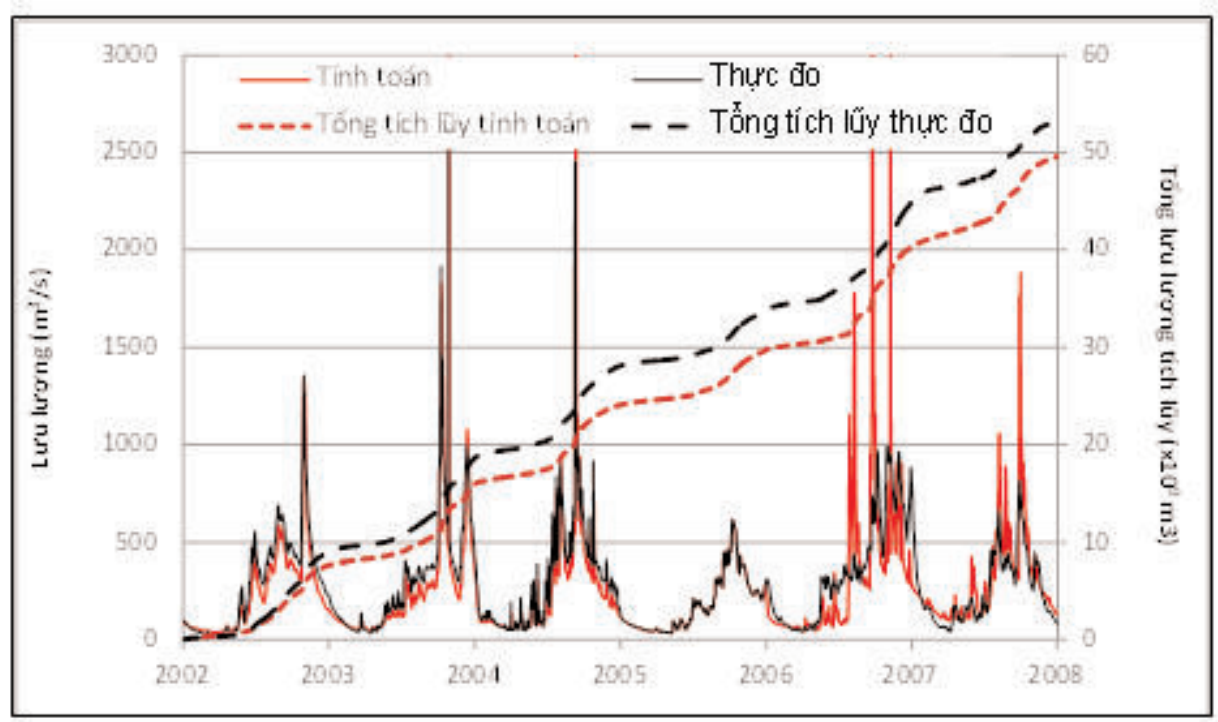

Hình 4: Đường quá trình lưu lượng tính toán và thực đo tại trạm thuỷ văn Luang Prabang 
Bảng 2 thể hiện các chỉ số thống kê đánh giá độ chính xác kết quả mô phỏng thủy văn trong pha hiệu chỉnh mô hình SWAT. Đối với hai trạm Pakbeng và Luang Prabang, Chỉ số Nash-Sutcliffetương ứng là 0.78 và 0.71 ; sai số tổng lưu lượng tích lũy là $7.11 \%$ và $8.23 \%$, giá trị này vẫn nằm trong giới hạn cho phép $(-/+10 \%)$. Kết quả trên, có thể khẳng định bộ thông số trong bảng 1 đã được kiểm nghiệm và có thể sử dụng để tính toán sự biến động dòng chảy mặt ở khu vực phía bắc Lào do ảnh hưởng của biến động sử dụng đất ở khu vực này.

\section{2. Ảnh hưởng của biến động sử dụng đất đến dòng chảy mặt}

4.2.1. Phân tích biến động sử dụng đất khu vực phía bắc Lào giai đoạn 20002010

Bảng 3 thể hiện biến động sử dụng đất 4 tỉnh phía bắc Lào trong giai đoạn 20002010. Số liệu trong bảng 3 cho thấy có sự biến động cơ cấu sử dụng đất mạnh mẽ trong khu vực; với nhóm đất rừng bị suy giảm mạnh trong khi đất nông nghiệp, đất cỏ bụi và đất dân cư tăng đáng kể. Sự biến động này được giải thích là do một phần diện tích đất rừng bị khai thác gỗ hoặc chặt phá để sử dụng vào mục đích canh tác nông nghiệp; đồng thời do sự phát triển kinh tế-xã hội và sự gia tăng dân số kéo theo sức ép phát triển cơ sở hạ tầng, nên diện tích đất xây dựng đã không ngừng mở rộng. Nếu tính theo diện tích, đất rừng thường xanh giảm rất mạnh, khoảng 462810 ha (xấp xỉ $10 \%)$; tương tự như vậy, diện tích đất rừng rụng lá và rừng hỗn giao cũng giảm tương ứng khoảng 7000 ha và 24735 ha. Ngược lại, diện tích đất cỏ bụi, đất nông nghiệp và đất dân cư tăng tương ứng 398627 ha, 93279 ha và 5035 ha.

Bảng 3: Biến động sử dụng đất khu vực phía bắc Lào

\begin{tabular}{|l|c|c|c|c|}
\hline \multirow{2}{*}{ Tên lớp Thời gian } & \multirow{2}{*}{$\begin{array}{c}\text { Năm 2000 } \\
\text { (ha) }\end{array}$} & \multirow{2}{*}{$\begin{array}{c}\text { Năm 2010 } \\
\text { (ha) }\end{array}$} & \multicolumn{2}{c|}{ Biến động 2000-2010 } \\
\cline { 4 - 5 } & & & Diện tích (ha) & Tỷ lệ (\%) \\
\hline Nước & 102880.73 & 102483.95 & -396.78 & -0.01 \\
\hline Rừng thường xanh & 2465557.71 & 2002747.99 & -462809.72 & -9.97 \\
\hline Rừng rụng lá & 9065.20 & 1918.90 & -7146.30 & -0.12 \\
\hline Rừng hỗn giao & 2662041.90 & 2637306.79 & -24735.10 & -0.41 \\
\hline Rừng cây bụi & 285165.03 & 282225.32 & -2939.71 & -0.05 \\
\hline Cỏ bụi & 51346.97 & 449974.11 & 398627.14 & 6.64 \\
\hline Đồng cỏ & 181016.83 & 173723.31 & -7293.52 & -0.12 \\
\hline Đầm lầy & 10379.19 & 17364.07 & 6984.87 & 0.12 \\
\hline Đất nông nghiệp & 227908.29 & 321187.53 & 93279.24 & 3.81 \\
\hline Đất xây dựng & 5548.43 & 10583.62 & 5035.19 & 0.08 \\
\hline Đất trống & 326.68 & 1721.36 & 1394.68 & 0.02 \\
\hline
\end{tabular}




\subsection{1. Đánh giá ảnh hưởng của biến động sử dụng đất đến dòng chảy mặt}

Như phần trên đã phân tích, có thể thấy rằng diện tích đất rừng bị giảm đi tương ứng khoảng $10 \%$ tổng diện tích đất của 4 tỉnh trong khu vực nghiên cứu. Trong phần này, chúng tôi sẽ đánh giá sự biến động sử dụng đất nói chung và đặc biệt là sự suy giảm diện tích lớp phủ rừng có ảnh hưởng như thế nào đến lưu lượng dòng chảy trong khu vực. Để đánh giá những ảnh hưởng trên, chúng tôi tiến hành tính toán, phân tích bằng mô hình SWAT với bộ thông số của mô hình đã được hiệu chỉnh ở phần trên (trong bảng 1). Chuỗi số liệu lượng mưa trong thời kỳ từ 2000 đến 2008 (như trong pha hiệu chỉnh) vẫn tiếp tục được sử dụng. Điểm khác biệt trong pha đánh giá (pha 2) là chúng tôi sử dụng số liệu lớp phủ thực vật năm 2010 thay cho số liệu năm 2000. Kết quả tính toán dòng chảy trung bình tháng trên lưu vực sông Nam-Beng (vị trí mặt cắt cửa ra tại Pakbeng) và lưu vực sông Nam Khan (vị trí mặt cắt cửa ra tại Luang Prabang) được thể hiện trong hình 5 dưới đây. (Xem hình 5)

Trên hình 5 cho thấy, lưu lượng dòng chảy tương ứng với số liệu sử dụng đất năm 2010 giảm trung bình năm khoảng $2 \%$ (tại trạm đo Pakbeng) và 13\% (tại trạm đo Luang Prabang). Tuy nhiên sự biến động dòng chảy là không đồng đều trong cả năm.
Tại Pakbeng, lưu lượng đỉnh lũ tăng trung bình $1 \%$ và lưu lượng dòng chảy mùa khô giảm trung bình $1.2 \%$, giảm mạnh nhất là vào tháng 2 , khoảng $3 \%$. Trong khi đó, tại tram Luang Prabang cho thấy ảnh hưởng của biến động sử dụng đất đến dòng chảy theo mùa rõ rệt hơn: lưu lượng đỉnh lũ tăng trung bình $3.6 \%$,cao nhất là tháng 9 với lưu lượng đỉnh lũ có thể tăng xấp xỉ $6 \%$; lưu lượng dòng chảy mùa khô giảm khá mạnh, mức giảm trung bình khoảng $4.5 \%$, cá biệt vào tháng 1 có thể giảm đến gần $8 \%$. Sự suy giảm dòng chảy mặt như trên cho thấy biến động sử dụng đất là yếu tố thực sự có ảnh hưởng; trong đó sự giảm diện tích rừng thường xanh được xem là nguyên nhân chính (diện tích rừng thường xanh giảm gần $10 \%)$. Điểu này có thể được giải thích là sự suy giảm diện tích rừng trong khu vực dẫn giảm khả năng giữ nước vào mùa mưa làm tăng đỉnh lũ; trong khi mất rừng làm tăng khả năng bốc thoát hơi nước, dẫn đến giảm dòng chảy vào mùa khô.

\section{Kết luận}

Việc sử dụng viễn thám, GIS và tích hợp với mô hình thủy văn cung cấp một công cự tin cậy và hiệu quả trong giám sát diễn biến dòng chảy mặt của lưu vực sông. Cũng giống như nhiều nước đang phát triển ở khu vực Đông Nam Á, Lào đang chứng kiến sự chuyển đổi mạnh mẽ diện tích rừng sang nhiều mục đích khác nhau như phục vụ thủy
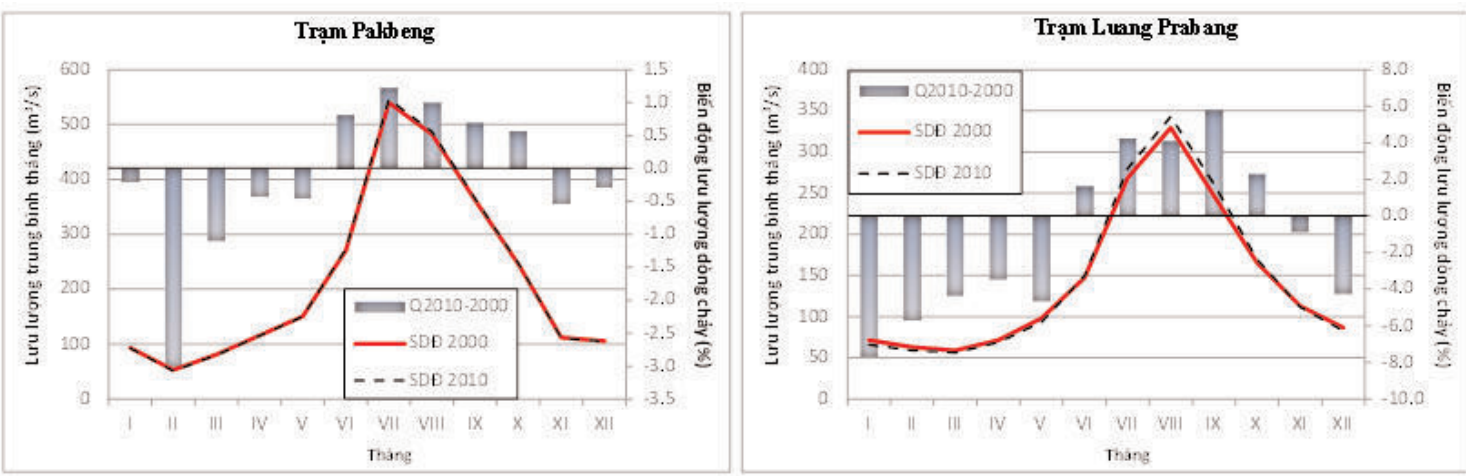

Hình 5: Diễn biến dòng chảy khu vực phía bắc Lào do ảnh hưởng của biến động sử dụng đất 
điện, nông nghiệp, giao thông,.. trong hàng chục năm qua, trong đó diện tích rừng đã bị mất đi khoảng $10 \%$.

Mô hình thủy văn SWAT với bài toán đường cong số (Curve Number) áp dụng trên các lưu vực sông nhánh của dòng Mekong ở khu vực phía bắc Lào cho thấy xu hướng dòng chảy giảm mạnh, đặc biệt là trên lưu vực sông Nam Khan (tại trạm Luang Prabang). Thông qua việc mô hình hóa, có thể thấy rằng những thay đổi sử dụng đất, đặc biệt là sự suy giảm diện tích rừng có ảnh hưởng trực tiếp đến suy giảm dòng chảy mặt vào mùa khô và tăng đỉnh lũ vào mùa mưa. Điều này có thể dẫn đến những tác động không mong muốn như tăng khả năng hạn hán vào mùa khô trong khi tăng khả năng lũ lụt vào mùa mưa. $O$

\section{Tài liệu tham khảo}

[1]. Anderson JR và nnk., 1971. Landuse classification schemes used in selected recent geographic applications of remote sensing: Photogramm.Eng., v. 37, no. 4, p. 379-387.

[2]. Arnold, J. G., R. Srinivasan, R. S. Muttiah, and J. R. Williams.1998.Large area hydrologic modeling and assessment.Part 1:Model development. J. Am. Water Res. Assoc. 34(1): 73-89.

[3]. ASTER GDEM. Trang điện tử http://gdem.ersdac.jspacesystems.or.jp/. Truy cập và tải dữ liệu tháng 7/2015.

[4]. DMH. Cục Khí tượng và Thủy văn, Bộ Tài nguyên và Môi trường Lào.

[5]. Eastman R J, (2003).IDRISI Kilimanjaro Guide to GIS and Image Processing. Clark University. Chapitre 16, pp 201-227.

[6]. LNMC: Ủy ban quốc gia sông Mê Công Lào, thuộc Ủy hội sông Mê Công quốc tế.

[7]. Nghiem V-T, Nedjai R and Messaoud
N.N, (2011). The consequences of changes in forest land cover in the Alpine and Jurassic massifs on the physico-chemical status of deep lake waters. Journal of Alpine Research.99-3 | 2011, 12p. Mis en ligne le 21 février 2012. URL :http://rga.revues.org/1611; DOI: 10.4000/rga.1611.

[8]. Rachid Nedjai, Van-Tuan Nghiem, Abelhamid Azaroual, Laurent Touchart, Nasredine Messaoud-Nacer, (2013). Water Resource Decrease Due to Land-Use Changes in the French Jura Mountains: A Combined Use of the SWAT Model and Land Cover Modeling to Evaluate the Global Trend. American Journal of Environmental Engineering, 3(5): 225-235.

[9]. Rallison, R. E., and N. Miller. 1981. Past, present, and future SCS runoff procedure. In Rainfall Runoff Relationship, 353364, ed.

[10]. Richards J A et Jia X,.(2006), Remote Sensing Digital Image Analysis, Book of Springer -Verlag Berlin Heidelberg. Pp 454

[11]. Rosenbrock HH. 1960. An automatic method of finding the greatest or least value of afunction. Computer Journal 3: 175-184.

[12]. Shrestha, M. S., Artan, G. A., Bajracharya, S. R., and Sharma, R. R. (2008). Using satellite-based rainfall estimates for streamflow modeling: Bagmati Basin, J. Flood Risk Manage., 1, 89-99, 2008.

[13]. Soil Conservation Service. 1972. Section 4: Hydrology In National Engineering Handbook. SCS.USGS. Co' quan khảo sát địa chất Hoa kỳ: thông qua trang điện tử http://earthexplorer.usgs.gov/.Truy cập và tải dữ liệu tháng 7/2014. 0 